\title{
Televisão Peruana em 14 Perspectivas $^{1}$
}

\author{
Peruvian Television in 14 Perspectives
}

Televisión Peruana en 14 Perspectivas

Paulo NEGRI FILHO²

CASSANO, Giuliana (Editora). Televisión: 14 formas de mirarla. Lima, Perú: Departamento Acadêmico de Comunicaciones, PUCP, 2010.

No marco de 50 anos da TV no Peru, em 2008 o Departamento Acadêmico de Comunicações da Pontifícia Universidade Católica do Peru organizou um seminário internacional para discutir e refletir sobre a televisão. Uma seleção das apresentações realizadas é o que compõe "Televisão: 14 formas de olhá-la", dividida em três partes, sendo: "A televisão: uma experiência vital"; "50 anos de televisão no Peru"; e "A televisão peruana hoje: continuidade e dinamismo".

As três partes são compostas por catorze textos de diferentes pesquisadores e que apresentam perspectivas diversas. A primeira parte é a mais ampla, a que trata da televisão como meio de comunicação com características comuns a qualquer país, com foco especial aos latino-americanos. A segunda parte se destaca por ser um panorama dos 50 anos da televisão peruana, buscando elementos de sua história. A terceira e última parte trata das características da televisão peruana hodierna, algumas vezes retomando sua história, mas sempre na expectativa de elucidar seu presente e seu futuro, tanto na capital, quanto no interior.

Já na apresentação da coletânea, feita por Dettleff, fica evidente a importância da televisão na sociedade do século XX, assim como a curiosidade, a fascinação e a rejeição por ela provocada. Dettleff aponta para o modo negativo como a televisão é vista, segundo ele, impulsionada pela academia não só no Peru, como em outros países.

Há uma cobrança social para que a televisão seja aquilo para o qual ela não foi criada. A televisão parece menos sólida do que já foi há uma década justamente porque suas audiências

1 Resenha apresentada à oitava edição da Revista Ação Midiática - Estudos em Comunicação, Sociedade e Cultura, publicação ligada ao Programa de Pós-Graduação em Comunicação, da Universidade Federal do Paraná.

2 Doutorando em Ciências da Comunicação - CAPES 6 (Unisinos), mestre em Educação - CAPES 6 (UFPR), especialista em Comunicação Visual em Mídias Interativas (Unopar) e bacharel em Comunicação Social - Publicidade e Propaganda (Imesa). Tem experiência na área de Comunicação, com ênfase em Videodifusão e Imprensa, atuando principalmente nos seguintes temas: Audiovisual, Tecnologia da Informação e Comunicação, Comunicação Corporal, Mídia Eletrônica, Mídia Impressa e Arte. Coordenador do curso de Publicidade, Propaganda e Marketing do Centro Universitário Internacional Uninter. Coautor do livro "Produzindo textos com "velhas" e "novas" tecnologias', com a Profa. Dra. Gláucia da Silva Brito. E-mail: paulonegrifilho@gmail.com. 


\section{açã(g) Midiática \\ № 8 | Ano 2014}

estão cada vez mais dispersas e com interesses mais fragmentados.

Para dar conta da multiplicidade de aspectos abordados na obra, como é, também, a proposta da mesma, optou-se por apresentar, ainda que brevemente, cada um dos capítulos, na mesma ordem em que aparecem em "Televisão: 14 formas de olhá-la".

Em "TV: o afeto cristão", primeira parte da coletânea, Muniz Sodré privilegia a dimensão do imaginário, dimensão essencial de uma cultura do afeto, que parece definir a esfera do audiovisual. O autor afirma que a imagem é, ao mesmo tempo, enigmática e paradoxal. Enigmática porque se apresenta sempre como "quase-alguma-coisa" e paradoxal porque, junto à sua banalidade, há toda uma história cristã, uma vez que possibilitava a aparição material de algo imaterial. O cristianismo introduziu a paixão pela imagem. Contudo, há uma ambiguidade na palavra imagem que remete à divindade e que reveste os meios eletrônicos de características como simultaneidade, instantaneidade e ubiquidade.

Nora Mazziotti, em "A telenovela e sua hegemonia na América Latina: a paixão pelos relatos", afirma que a narração faz parte da cultura, uma vez que em todas as culturas há histórias e que um fio une os que escutavam relatos ao redor do fogo, os que ajeitavam suas cadeiras próximo ao rádio e que, atualmente, fazem-no na frente da televisão.

$\mathrm{Na}$ América Latina, a telenovela remonta à própria existência da televisão, sendo o produto cultural de maior circulação internacional. A imitação das novelas latino-americanas estende-se a lugares remotos, uma vez que a linguagem do melodrama, a apelação e a emoção da telenovela e a paixão pela narração são capazes de ir muito longe.

Dos estilos de telenovelas, três modelos consolidados podem ser identificados: o mexicano, o brasileiro e o colombiano; dois modelos descontinuados: o argentino e o venezuelano; e um modelo global realizado com capital norte-americano.

"Audiências e telas. O novo, o velho e o que vem" é o último capítulo da primeira parte da coletânea, em que Guillermo Orozco Gómez alerta para a necessidade de se repensar o estudo de recepção tanto das velhas quanto das novas telas que têm, não apenas se multiplicado quantitativamente, como também se transformando qualitativamente de maneira significativa. $\mathrm{O}$ autor aponta para três motivos principais: a interatividade que as novas telas permitem; a convergência entre telas, denominada "televidência"; e a individualização de telas, cada vez mais pessoais e portáteis, quase próteses comunicantes dos indivíduos que as portam.

São caracterizadas as mudanças para que se possam repensar suas consequências para o entendimento tanto das novas audiências como do exercício da investigação de seus múltiplos processos de interação com as telas.

Orozco Gómez pontua "o novo" para, na sequência, chamar atenção para aquilo que se modificou, "o velho", identificando o que prevalece e os vestígios desejáveis e os indesejáveis que podem ser reconhecidos. O último tópico “o que vem”, vai para além de uma predição, com a 


\section{açã(g) Midiática \\ № 8 I Ano 2014}

antecipação dos cenários possíveis para o exercício de uma investigação comunicacional produtiva.

A segunda parte da obra é aberta por Luis Jochamowitz, com "A impossível história da televisão", em que a aparência contraditória de uma história da televisão é evidenciada pelo fato de história pressupor passado e registro e, sendo a televisão instantânea, dissolver-se no presente. O próprio videoteipe, que, a partir de 1962, teria a função de registrar a história da TV peruana, teve seus arquivos perdidos, restando poucos materiais da década de 1960.

Apenas nos anos 1980 e 1990 houve uma preocupação em se conservar a memória televisiva do país, em forma de imagem.

No decorrer dos anos de 1960 a TV foi se tornando menos rígida e se soltando das "amarras" do rádio. O alcance da televisão se deu de forma exponencial, não se limitando à cidade de Lima, no entanto esse crescimento não foi visto na programação. O que parecia ser a década de ouro da televisão, mas que era, na verdade, uma visão ingênua, começou a mudar na década de 1970, com intervenção militar e, muito mais, na década seguinte.

Além das mudanças demográficas, sociais e culturais, a importância da TV se dá por ser parte central do mundo. Para exemplificar a centralidade da televisão, Jochamowitz ressalta que a verdadeira arma do 11 de setembro, por exemplo, não foram os aviões transformados em mísseis derrubando edifícios, mas a emoção aterradora disseminada pela televisão para meia humanidade.

"Imagens televisivas: poder e responsabilidade. Desafios e oportunidades para os comunicadores sociais" é o texto em que María Teresa Quiroz opta por analisar a televisão atual na expectativa de explicar o passado e projetar o futuro, tendo por finalidade propor alternativas para os cidadãos em geral e para a formação de comunicadores sociais audiovisuais. Para a autora, houve pouca mudança nos conceitos e nas estratégias empresariais, assim como na inovação dos conteúdos e na qualidade das propostas da televisão peruana.

Nesses 50 anos, a televisão no Peru esteve vinculada ao poder político, em etapas distintas. O acesso à TV aberta se aproxima dos 100\% em Lima sendo massivo também nas demais cidades do país. Mesmo assim, tem crescido o acesso à TV a cabo, sendo preferida, inclusive, por ser um fator de diferenciação social.

Teresa Quiroz apresenta diversos quadros com dados referentes à realidade televisiva peruana, como a tendência de TV em domicílios, a tendência da TV PB/colorida e o parque televisivo, os números da TV a cabo, a preferência por TV aberta e a cabo, a assistência de noticiários e programas políticos, a confiança em programas políticos de televisão, os meios para se informar sobre temas políticos, o consumo de meios, a confiança nos meios, a ficção estrangeira exibida no Peru e os formatos de ficção nacional.

A autora reforça, ainda que brevemente, a importância de se pensar a TV digital para além de uma reflexão tecnológica, senão para as possibilidades de transformação permitidas pelo 
meio. Também brevemente, trata das imagens e da educação, ressaltando que os mais jovens sabem mais pelo que viram e ouviram do que pelo que leram. Resgata de Arlindo Machado a crítica na crença na palavra escrita como única fonte de verdade.

Para finalizar, a pesquisadora apresenta os novos profissionais da comunicação, com base em quatro reflexões: a) entretenimento não pode ser separado de informação e de educação; b) o mundo acadêmico não pode permanecer à margem do entretenimento, do espetáculo e da narração; c) a formação dos consumidores deve ser humanística, para além da tecnológica; d) é necessário que haja uma TV pública que se baseie na complexidade da realidade espacial e cultural do país e dos diferentes atores sociais, oferecendo pluralismo social, ideológico e político.

Alberto Beingolea, em "A televisão como espaço esportivo", resgata o início da TV peruana no ano de 1958 com a América Televisión, depois de agosto a dezembro de 1959 com o Canal 9 e, então a Panamericana Televisión. Apesar da breve existência, o Canal 9 fez um grande aporte esportivo, o que permite dizer que o esporte chega à televisão, no Peru, quase com o nascimento desta. $\mathrm{O}$ autor faz um resgate das transmissões esportivas no Peru, especialmente pela América Televisión e Panamericana Televisión. Assinala que o grande show do futebol na televisão é visto no mundial do México de 1970. Desde a década de 1960, no entanto, eram transmitidas corridas de cavalo.

Com a Tupi, que se forma em 1968, o campeonato da primeira divisão tem transmissões estáveis em 1968 e 1969. No entanto, ainda se fazia rádio na televisão, e só na década de 1990 se fez televisão na televisão, especialmente com o programa "Acción".

A terceira e última parte da obra é aberta com o texto "Para a formulação de políticas de televisão para a mudança digital”, de Gerardo Arias Carbajal, que pontua que até o momento da finalização do mesmo, não havia sido adotada, no Peru, oficialmente, a TV digital terrestre, cujo modelo escolhido foi publicado em abril de 2009, sendo a nipo-brasileira. Mas, para o autor, mais importante que a matriz adotada, a discussão deve se dar em torno de para que se quer a televisão digital, uma vez que a mudança apenas para a melhoria da qualidade de imagens dos programas de sempre não é válida.

A implementação da TV digital, sem políticas públicas para uma mudança real na televisão, além de maquiar, poderia agravar os problemas estruturais, gerando outros. Assim, Arias Carbajal defende o ingresso de novos operadores que, além de fins comerciais, mobilizassem cultura, educação, política, religião, dentre outros.

O ingresso desses novos operadores dinamizaria a indústria televisiva e o consequente aumento de oferta de conteúdos. Assim, também, seria desejável a descentralização dos critérios limenhos. A interatividade é outro fator questionado, uma vez que não existem políticas de incentivo para desenvolvimento de conteúdos lúdicos e criativos. 
Para o autor, independentemente do dispositivo de recepção, a TV aberta deveria ser gratuita, aproveitando-se, por exemplo, da expansão do número de telefones celulares no país. Outra discussão importante é sobre a opção pela televisão de alta definição ou pela televisão digital standart, com qualidade inferior, mas com possibilidade de mais canais por banda.

Em "A indústria de ficção televisiva no Peru", Alfonso Pareja afirma que, apesar de alguns sucessos internacionais de séries e telenovelas peruanas, a produção ficcional do país não tem se sustentado. E isso não se dá por falta de qualidade em âmbito internacional, uma vez que no Peru existem diretores, roteiristas, produtores, pessoal técnico e artístico bem preparados.

Nos anos de 1966 e 1971 a indústria de ficção peruana era promissora, mas no início dos anos de 1970 o governo militar desapropriou canais de televisão, o que atrapalhou o desenvolvimento da ficção no país. Apesar da volta dos meios aos seus proprietários na década de 1980, na segunda metade dessa década, a crise econômica foi o empecilho do desenvolvimento da indústria de ficção. Apenas na década de 1990 houve a reativação efetiva da ficção no Peru, puxada pela diversidade de empresas participantes.

Não só questões políticas, mas econômicas vão interferir na baixa produção da indústria ficcional peruana. Falta ao Peru reconhecer que arte e indústria se fundem na ficção, não se excluindo.

Renato Canales Montoya, em “A televisão como espaço político”, destaca que no início da televisão peruana houve uma forte tendência ao entretenimento, isto porque o contexto político limitava, por exemplo, a ação do jornalismo. Só nos primeiros anos de democracia os programas jornalísticos voltaram à ativa com forte dose de temas políticos.

Uma pesquisa do Grupo de Opinión Pública da Universidade de Lima, realizada no último fim de semana de junho de 2008, mostrou que de Lima a Callao, 62,6\% das pessoas buscaram noticiários para se informar.

Canales Montoya salienta o papel fiscalizador da imprensa em qualquer meio, com destaque especial para a televisão, pela sua cobertura massiva e preferência da população.

No mesmo sentido, o texto “Televisão: suas relações com o poder”, de Santiago Pedraglio, aponta que a relação da televisão com a política está intimamente ligada ao governo no poder e à independência (ou não) do meio, sendo muito mais fácil para os jornalistas investigarem e denunciarem o Parlamento ou o Poder Judiciário do que o Poder Executivo, visto com mais cautela.

Investigação e denúncia são ainda mais difíceis ao se falar do poder econômico. A televisão no Peru não expressa apenas interesses jornalísticos, mas, também, de grupo empresarial, não sendo formada por conglomerados midiáticos, como acontece na Argentina, no Brasil, na Venezuela, na Colômbia e no México.

Giuliana Cassano, por outro lado, em “A televisão como reconhecimento da diversidade”, 


\section{açã(g) Midiática \\ № 8 I Ano 2014}

vai abordar o meio na sua perspectiva cultural, configurando campos e redes de significação que, para a autora, referem-se à característica de mediação social, aqueles espaços de diálogo, de negociação e de reconhecimento do "Outro". Assim como a cultura não é um termo no singular, mas plural e democrático, a televisão enquanto espaço cultural assume característica da cultura, sendo definida por meio de formas simbólicas variadas que configuram diversos campos de significação, um convite a explorar a multiplicidade de expressões, manifestações e interpretações nas quais cada uma das audiências se configuram e se realizam.

Essa introdução vai ter continuidade em Antonio Zapata, com “A televisão como espaço cultural", para quem, na medida em que a TV a cabo se expandiu, os programas culturais foram desaparecendo da televisão comercial de sinal aberto, concentrando-se na fechada ou na nacional, a TV Peru.

Zapata julga que o insucesso dos programas culturais no Peru tem a ver com o rating, a publicidade e a política. O rating, porque esse tipo de programa atinge cinco pontos em seu melhor dia, comparativamente seriam 100 pontos de um programa comercial de sucesso, o que o torna insustentável economicamente. O investimento publicitário tem diminuído, apesar de a economia estar em crescimento. Isto é reflexo de um mercado que, apesar de crescente, tem se monopolizado, o que torna menos necessário o uso da publicidade.

$\mathrm{Na}$ TV Peru, os programas políticos ocupam os melhores horários, em detrimento dos programas políticos, o que não incrementa a verba de anúncios para subsistência daqueles. $\mathrm{O}$ autor defende que a TV governamental deveria oferecer alternativa frente aos outros canais, fomentando, principalmente, a cultura.

"Cultura, identidade e negócio: a realidade das televisões locais e sua perspectiva de futuro", de James Dettleff, expõe que o Peru vê sua realidade pelos "olhos" limenhos, escutando mensagens televisivas da perspectiva da capital. O país é centralista e isto se reflete na sua televisão com pouca presença das emissoras locais. Essa realidade tem se agitado, na medida em que, nos últimos anos, novas concessões estão sendo direcionadas para emissoras regionais que transmitem e produzem localmente. Se já existe grande distância tecnológica entre as grandes emissoras e as regionais, com a possibilidade da TV digital terrestre é duvidoso o futuro das menores.

Em uma perspectiva mais otimista, Carlos Cárdenas, em "Emissoras locais: multiplicando telas", apresenta dados retirados do artigo sobre os "Movimentos no Quarto Poder", em que afirma que, apesar de o Peru configurar o menor número de emissoras de TV da América Latina em 2008, com 11 canais, o Ministério de Transportes e Comunicações apresenta números bem diferentes, 1048 autorizações, no mesmo ano.

O abismo entre os números é justificado por Cárdenas pelo fato de que o que é visto nas diversas localidades do país é diferente, ainda que se sintonize o mesmo canal. Isto pela 


\section{ação) midiática \\ Estudos em Comunicação, Sociedade e Cultura \\ № 8 I Ano 2014}

multiplicação das telas locais. O autor participa de uma associação nacional de canais locais (REDTV) que, em 2004, contabilizou 154 estações de televisão diferentes dos canais de Lima. Dentre as estações, muitas municipais, que sequer configuram os números de autorizações do Ministério de Transportes e Comunicações.

O texto é finalizado com o questionamento sobre a maneira como os dados são lidos, o que, muitas vezes, mascara a realidade. 